\title{
History of influenza immunization in COVID-19 patients: impact on mortality
}

\author{
Carlos Sánchez-García, ${ }^{1 *}$ Juan E. Salinas-Aguirre, ${ }^{2}$ Lorena Rodríguez-Muñoz, ${ }^{1}$ Raúl Rodríguez-Sánchez, ${ }^{2}$ \\ Angélica Díaz-Castaño ${ }^{1}$ and Roberto Bernal-Gómez ${ }^{1}$ \\ ${ }^{1}$ Technical Committee for the Prevention, Care and Control of COVID-19; ${ }^{2}$ Department of Epidemiology, Secretaría de Salud del Estado de Coahuila \\ de Zaragoza,. Coahuila, México
}

\begin{abstract}
Introduction: In the context of the COVID-19 pandemic, there is concern regarding the impact of the influenza season. Objective: To analyze the impact of influenza immunization history on patients with SARS-CoV-2 infection. Methods: Patients older than 18 years with COVID-19, registered between March and August 2020, were included. Data were analyzed using Fisher's exact test and Student's t-test. To evaluate the impact on mortality, a logistic regression model was used; the relationship between the percentage of patients who received the influenza vaccine and mortality was determined with Pearson's correlation coefficient. Results: 16,879 participants were included; $17 \%$ had a history of influenza vaccination. Mortality was lower in the group with a history of vaccination (3.5 \% vs. $7 \%, p<0.0001)$. The vaccination rate had an inverse relationship with the mortality rate (Pearson's $r$ : $-0.922, p=0.026)$. Conclusions: Previous influenza immunization was an independent protective factor for mortality in patients with COVID-19. Although further studies are needed to determine a causal relationship, it would be reasonable to increase influenza immunization in the general population.
\end{abstract}

KEY WORDS: SARS-CoV-2. COVID-19. Immunization. Influenza. Mortality.

\section{Antecedente de inmunización contra influenza en pacientes con COVID-19: impacto en la mortalidad}

\section{Resumen}

Introducción: En el contexto de la pandemia de COVID-19 existe inquietud en cuanto al impacto de la temporada de influenza. Objetivo: Analizar el impacto del antecedente de inmunización contra influenza en pacientes con infección por SARSCoV-2. Métodos: Se incluyeron pacientes mayores de 18 años con COVID-19, registrados entre marzo y agosto de 2020. Los datos fueron analizados mediante las pruebas exacta de Fisher y $t$ de Student. Para evaluar el impacto en la mortalidad se utilizó un modelo de regresión logística; la relación entre el porcentaje de pacientes a quienes se aplicó la vacuna contra la influenza y la mortalidad fue determinada con el coeficiente de correlación de Pearson. Resultados: Se incluyeron 16879 participantes; $17 \%$ tuvo antecedente de vacunación contra influenza. La mortalidad fue menor en el grupo con historia de vacunación $(3.5 \%$ versus $7 \%, p<0.0001)$. El porcentaje de vacunación presentó una relación inversa con el porcentaje de mortalidad ( $r$ de Pearson - 0.922, $p=0.026$ ). Conclusiones: La inmunización contra la influenza fue un factor protector independiente de mortalidad en pacientes con COVID-19. Aunque son necesarios más estudios para determinar la relación causal, será razonable incrementar la inmunización contra influenza en la población general.

PALABRAS CLAVE: SARS-CoV-2. COVID-19. Inmunización. Influenza. Mortalidad.

\footnotetext{
Correspondence:

${ }^{*}$ Carlos Sánchez-García

E-mail: sanchez.carlos8516@gmail.com

Gac Med Mex. 2021;157:102-106

Contents available at PubMed

www.gacetamedicademexico.com

0016-3813/@ 2020 Academia Nacional de Medicina de México, A.C.. Published by Permanyer. This is an open access article under the CC BY-NC-ND license (http://creativecommons.org/licenses/by-nc-nd/4.0/).
} 


\section{Introduction}

In December 2019, the presence of cases of pneumonia of unknown cause was reported in the city of Wuhan, China; subsequently, the authorities identified a new coronavirus (SARS-CoV-2) as the causative agent of the disease (COVID-19). On March 11, 2020, the SARS-CoV-2 infection was declared a pandemic and on February 27, 2020, the first case in Mexico was reported. ${ }^{1}$

As the COVID-19 pandemic has evolved, concerns have been raised about the impact the flu season might have. ${ }^{2}$ Influenza is a significant cause of morbidity and mortality and use of health services around the world; the second wave of the pandemic has coincided with the influenza season, a matter of concern among health authorities in different countries. ${ }^{3,4}$

The purpose of this study was to analyze the impact of the history of influenza immunization in patients with COVID-19, in order to implement measures that may impact on the severity of this disease.

\section{Methods}

The study design is of the retrospective cohort type. Data were obtained from the Respiratory Diseases Surveillance System, included in the National Epidemiological Surveillance System of the General Directorate of Epidemiology, Ministry of Health of Mexico. The Research Ethics Committee approved the performance of the study; data that might individually identify each participant were not included.

Patients from the state of Coahuila de Zaragoza, Mexico, older than 18 years of age, with a SARSCoV-2 infection positive result obtained by real-time polymerase chain reaction, recorded between March 17 and August 16, 2020, were included.

For statistical analysis, the following variables were considered: age, gender, in-hospital treatment, need for mechanical ventilation, associated comorbidities (diabetes mellitus, hypertension, cardiovascular disease, obesity and chronic kidney disease), history of influenza immunization during the vaccination season prior to the study period and mortality.

Quantitative data were expressed with the mean and standard deviation, and qualitative data, with frequencies and percentages. Fisher's exact test and independent Student's t-test were used for comparison between groups.
The impact of a previous history of influenza immunization on mortality was evaluated using a univariate and multivariate logistic regression model. In the univariate logistic regression, all covariates were individually analyzed; those with statistically significant results were included in the multivariate analysis, adjusted for age and gender.

The difference in the percentage of mortality between the different age groups, according to a history or not of influenza immunization, was analyzed using Fisher's exact test; in addition, the relationship between the percentage of vaccinated patients and mortality among the different age groups was determined with Pearson's correlation coefficient. A p-value $<0.05$ was considered to be statistically significant. SPSS Statistics program, version 21.0 for Windows (IBM Corp., Armonk, NY, USA), was used for data analysis.

\section{Results}

A total of 16,879 participants were included, out of whom 8,487 were females $(50.3 \%)$ and 8,392 were males $(49.7 \%)$, with a mean age of 43 years; $13.8 \%$ required in-hospital treatment and $17 \%$ had a positive history of influenza vaccination. Overall mortality was $6.4 \%$ (1,081 patients).

Hypertension, obesity, diabetes mellitus, chronic kidney disease and cardiovascular disease were present in 13.9, 11.9, 10.9, 1.4, and $1.3 \%$ of patients, respectively.

Participants were divided according to positive or negative influenza immunization history; mean age was slightly higher in the group without a vaccination history (43.3 vs. 41.6 years), with a p-value $<0.0001$.

The proportion of patients older than 60 years of age was higher in the group without a history of vaccination $(p<0.0001)$. The percentage of participants with diabetes mellitus $(p=0.005)$, hypertension $(p<0.001)$ and obesity $(p<0.001)$ was higher in the group with a history of influenza immunization.

In the group with no vaccination history, $14.8 \%$ required in-hospital treatment and $0.9 \%$ required mechanical ventilation, in contrast with 9.2 and $0.3 \%$ in the group with a history of influenza immunization. Mortality was significantly lower in the group with a positive history of influenza vaccination ( $3.5 \%$ vs. $7 \%$ ), with a $p$-value $<0.0001$. The rest of patient characteristics are shown in table 1.

By means of univariate logistic regression, age older than 60 years, diabetes mellitus, hypertension, 
Table 1. Characteristics of COVID-19 patients according to the history of influenza immunization

\begin{tabular}{|c|c|c|c|c|c|}
\hline Characteristic & \multicolumn{2}{|c|}{$\begin{array}{l}\text { Immunization } \\
(n=2,905)\end{array}$} & \multicolumn{2}{|c|}{$\begin{array}{c}\text { No } \\
\text { immunization } \\
(n=13,974)\end{array}$} & p \\
\hline \multirow{2}{*}{$\begin{array}{l}\text { Age, years } \\
\text { (mean } \pm \text { SD) }\end{array}$} & \multicolumn{2}{|c|}{$41.6 \pm 13.9$} & \multicolumn{2}{|c|}{$43.3 \pm 15.3$} & \multirow[t]{2}{*}{$<0.0001$} \\
\hline & $\mathrm{n}$ & $\%$ & n & $\%$ & \\
\hline $\begin{array}{c}\text { Age group } \\
18-29 \\
30-39 \\
40-49 \\
50-59 \\
>60\end{array}$ & $\begin{array}{l}634 \\
803 \\
687 \\
456 \\
325\end{array}$ & $\begin{array}{l}21.8 \\
27.6 \\
23.6 \\
15.7 \\
11.2\end{array}$ & $\begin{array}{l}2944 \\
3301 \\
3202 \\
2402 \\
2125\end{array}$ & $\begin{array}{l}21.1 \\
23.6 \\
22.9 \\
17.2 \\
15.2\end{array}$ & $\begin{array}{c}0.369 \\
<0.0001 \\
0.397 \\
0.054 \\
<0.0001\end{array}$ \\
\hline Female gender & 1328 & 45.7 & 7159 & 51.2 & $<0.0001$ \\
\hline Diabetes mellitus & 372 & 12.8 & 1529 & 11 & 0.005 \\
\hline Hypertension & 503 & 17.3 & 1845 & 13.3 & $<0.0001$ \\
\hline $\begin{array}{l}\text { Cardiovascular } \\
\text { disease }\end{array}$ & 37 & 1.3 & 174 & 1.3 & 0.935 \\
\hline Obesity & 473 & 16.3 & 1531 & 11 & $<0.0001$ \\
\hline $\begin{array}{l}\text { Chronic kidney } \\
\text { disease }\end{array}$ & 42 & 1.4 & 208 & 1.5 & 0.926 \\
\hline In-hospital treatment & 266 & 9.2 & 2067 & 14.8 & $<0.0001$ \\
\hline $\begin{array}{l}\text { Mechanical } \\
\text { ventilation }\end{array}$ & 8 & 0.3 & 122 & 0.9 & 0.001 \\
\hline Mortality & 101 & 3.5 & 980 & 7 & $<0.0001$ \\
\hline
\end{tabular}

cardiovascular disease, obesity and chronic kidney disease were observed to be associated with increased mortality in patients with COVID-19 $(p<0.0001)$. A history of influenza vaccination was a protective factor against mortality, with an odds ratio (OR) of 0.47 being demonstrated, with a $95 \%$ confidence interval $(\mathrm{Cl})=0.38-0.58$.

These data were analyzed together using a multivariate logistic regression model, adjusted for age and gender. Although most covariates were shown to be independent risk factors for mortality, a history of influenza vaccination had an $\mathrm{OR}=0.44,95 \% \mathrm{Cl}=0.35$ 0.55 , with a $p$-value $<0.0001$, and thus it constituted an independent protective factor against mortality in patients with COVID-19 (Fig. 1).

The difference in the percentage of mortality between the participants with and without a history of vaccination according to each age group was shown to be larger with increasing age; it was larger in participants older than 60 years $(p=0.003)$ (Fig. 2).
Among the different age groups, the percentage of vaccination showed an inverse relationship with the percentage of mortality (Pearson's correlation coefficient -0.922), with a $p$-value $=0.026$ (Fig. 3).

\section{Discussion}

Different degrees of susceptibility to SARS-CoV-2 infection have been observed between different age groups, and these differences might be determined by the disparity in immune response (influenced by a history of previous infections and immunizations). ${ }^{5}$ There are some studies that assess the relationship between a history of influenza vaccination and a decrease in COVID-19 severity. ${ }^{6}$

In Italy, pneumococcal and influenza vaccines were reported to likely be associated with a lower probability of SARS-CoV-2 infection. ${ }^{7}$ In another study, a negative correlation was found between the percentage of deaths from COVID-19 and the percentage of adults older than 65 years with influenza immunization. ${ }^{8}$ In our study, we found this correlation; however, we analyzed the percentage of vaccination only in patients with COVID-19 and not in the general population, as it occurred in both Italian studies.

In two reports, which have not yet undergone peer review, one in the United States of America (Zanettini et al., 2020) and the other in Brazil (Fink et al., 2020), a potential protective effect of the influenza vaccine with regard to mortality in patients with COVID-19 is suggested.., 10

We found that, apparently, a history of influenza immunization constitutes an independent protective effect with regard to COVID-19 mortality; apparently, the difference is larger in patients older than 60 years of age, and thus, we agree with the referred studies.

To the best of our knowledge, this is the first study in Mexico and one of the few in Latin America to analyze the impact of a history of influenza vaccination in patients with COVID-19.

Although some studies have addressed the possible protective effect of influenza immunization on COVID-19 mortality, other factors might explain these findings.

Influenza immunization could, at least in part, promote immunity against SARS-CoV-2, due to the immune stimulus generated by this vaccine..$^{11}$ High rates of coinfection with SARS-CoV-2 and influenza virus have been reported. However, access to influenza vaccine may be related to a higher socioeconomic 


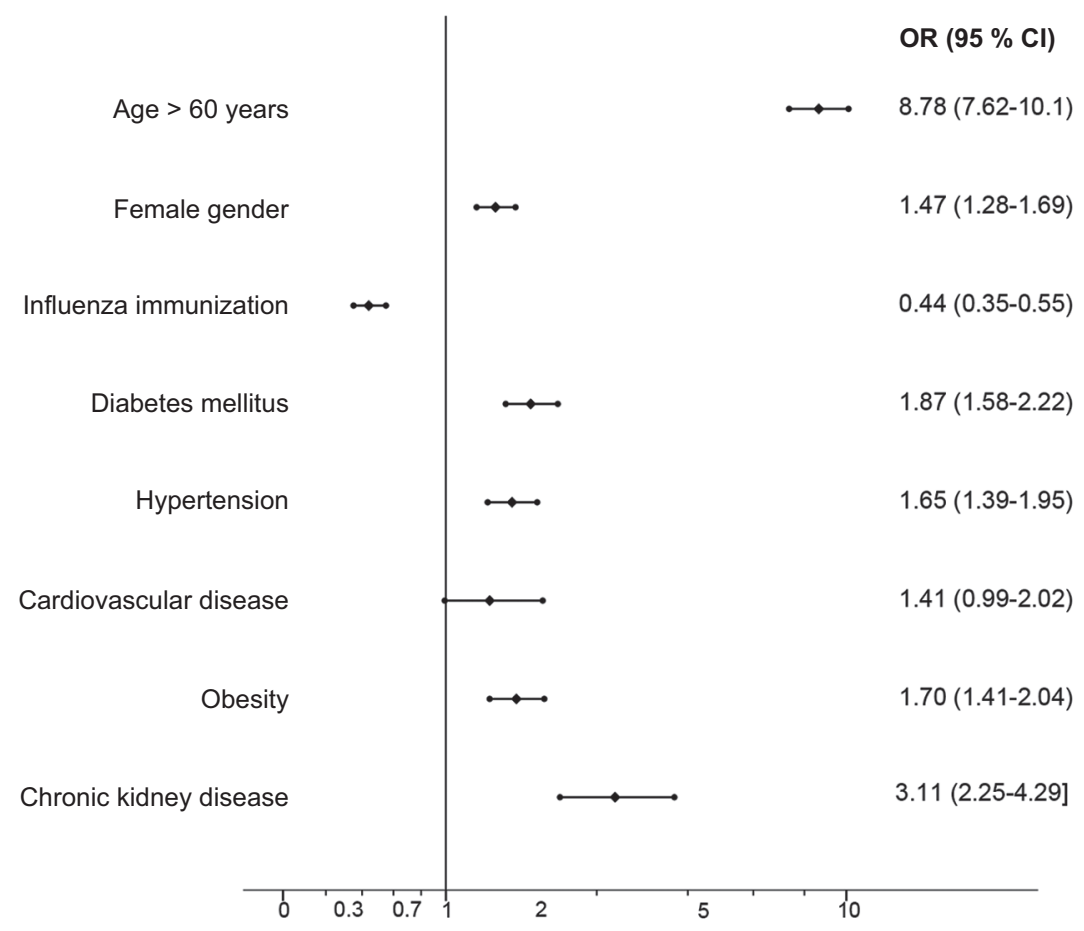

Figure 1. Multivariate analysis of factors related to mortality in patients with COVID-19. OR = odds ratio; $\mathrm{Cl}=$ confidence interval.

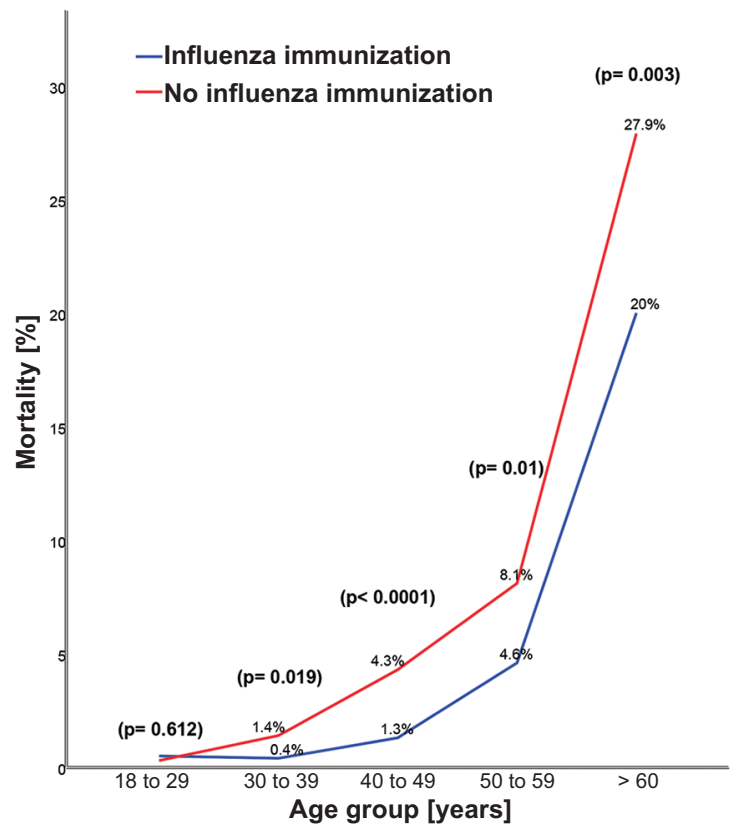

Figure 2. Comparison of mortality percentage between patients with and without a history of influenza immunization by age group.

stratus, which would be related to access to better health services. ${ }^{12-14}$ All these factors might contribute to the association between influenza immunization

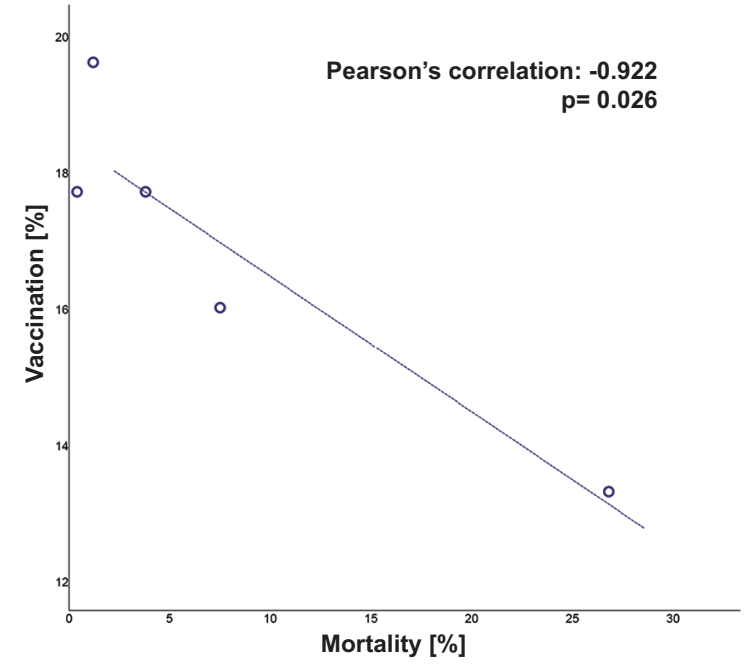

Figure 3. Correlation of the percentage of vaccinated patients between age groups and the percentage of mortality in patients with SARS-CoV-2 infection.

and SARS-CoV-2 infection, and the apparent protective factor might not be directly related.

We recognize the limitations of our study, such as its retrospective nature and the fact that the method for obtaining the data could be associated with biases. 
In conclusion, a history of influenza immunization appears to be an independent protective factor against mortality in patients with COVID-19; however, this result could have been produced by chance or by the discussed factors. Nevertheless, it is of great interest, since it could be a modifiable factor that would impact SARS-CoV-2 infection severity, hence the need for further studies in order to determine if there is any causal relationship. Despite the above, it is reasonable for efforts to be made in order to increase the percentage of influenza immunization in the population within the context of the COVID-19 pandemic.

\section{Conflict of interests}

The authors declare that they have no conflicts of interest.

\section{Funding}

The authors did not receive any sponsoring to carry out this article.

\section{Ethical disclosures}

Protection of human and animal subjects. The authors declare that no experiments were performed on humans or animals for this research.

Confidentiality of data. The authors declare that they followed the protocols of their work center on the publication of patient data.
Right to privacy and informed consent. The authors declare that no patient data appear in this article.

\section{References}

1. Suárez V, Suárez-Quezada M, Oros-Ruiz S, Ronquillo-de Jesús E. Epidemiología de COVID-19 en México: del 27 de febrero al 30 de abril de 2020. Rev Clin Esp. 2020;8:463-471.

2. Singer BD. COVID-19 and the next influenza season. Sci Adv. 2020;6:eabd0086.

3. Grech V, Borg M. Influenza vaccination in the COVID-19 era. Early Hum Dev. 2020;148:105116.

4. Maltezou HC, Theodoridou K, Poland G. Influenza immunization and COVID-19. Vaccine. 2020;38:6078-6079.

5. Salem ML, El-Hennawy D. The possible beneficial adjuvant effect of influenza vaccine to minimize the severity of COVID-19. Med Hypotheses. 2020;140:109752

6. Osaras R, Cirpin R, Duman H, Duran A, Arslan O, Leblebicioglu H. An open call for influenza vaccination pending the new wave of COVID-19. J Med Virol. 2020

7. Noale M, Trevisan C, Maggi S, Antonelli-Incalzi R, Pedone C, Di Bari M, et al. The association between influenza and pneumococcal vaccinations and SAS-CoV-2 Infection: data from the EPICOVID19 Web-Based Survey. Vaccines (Basel). 2020;8:471.

8. Marín-Hernández D, Schwartz RE, Nixon DF. Epidemiological evidence for association between higher influenza vaccine uptake in the elderly and lower COVID-19 deaths in Italy. J Med Virol. 2020;10.1002/jmv.26120.

9. Zanettini C, Omar M, Dinalankara W, Imana EL, Colantuoni E, Parmigiani G, et al. Influenza vaccination and COVID-19 mortality in the USA. medRxiv. Preprint. 2020 Jun 26.

10. Fink G, Orlova-Fink N, Schindler T, Grisi S, Ferrer AP, Daubenberger C, et al. Inactivated trivalent influenza vaccine is associated with lower mortality among Covid-19 patients in Brazil. medRxiv. Preprint. 2020. Dec 11

11. Zheng J, Perlman S. Immune responses in influenza A virus and human coronavirus infection: an ongoing battle between the virus and host. Curr Opin Virol. 2017;28:43-52.

12. Yue $H$, Zhang $M$, Xing L, Wang $K$, Rao X, Liu H, et al. The epidemiology and clinical characteristics of co-infection of SARS-CoV-2 and influenza viruses in patients during COVID-19 outbreak. J Med Virol. 2020;92:2870-2873.

13. Lucyk K, Simmonds KA, Lorenzetti DL, Drews SJ, Svenson LW, RusseII ML. The association between influenza vaccination and socioeconomic status in high income countries varies by measure used: a systematic review. BMC Med Res Methodol.. 2019;19:153.

14. Okoli GN, Abou-Setta AM, Neilson CJ, Chit A, Thommes E, Mahmud SM. Determinants of seasonal influenza vaccine uptake among the elderly in the United States: a systematic review and meta-analysis. Gerontol Geriatr Med. 2019:5:2333721419870345. 